\title{
The Impact of Arctic and North Atlantic Oscillation on Temperature and Precipitation Anomalies in Serbia
}

\author{
Pavlović Berdon Nada ${ }^{A}$
}

Received: December 2011 | First Revised: February 2012 | Accepted: June 2012

\begin{abstract}
The impact of the Arctic Oscillations [AO] and the North Atlantic Oscillations [NAO] is considered as the most prominent of atmospheric oscillations in the area of the northern hemisphere from the United States to Siberia and from the Arctic to the subtropical Atlantic. The aim of this study was to determine how these fluctuations affect the temperature and precipitation in Serbia.This paper explores the impact for the period of 50 years [1958-2007] by months and in 20 synoptic stations. The influence of the AO on temperature anomalies in Serbia can be seen by the correlation coefficient, the largest in the month of January, while its impact on precipitation is the largest in the month of February. After the test of linear correlation between the NAO index and temperature anomalies for the base period 1971-2000 for 20 synoptic stations in Serbia, it has been found that the highest correlation is in the month of January. The correlation between the NAO and the precipitation anomalies for the stations mentioned above is the highest in the month of February.Spatial patterns of the AO and the NAO influence on temperature in January and on precipitation in February were obtained by applying principal component analysis.
\end{abstract}

Key words: AO, NAO, temperature and precipitation anomalies, EOF, correlation

\section{Introduction}

Variations in temperature and precipitation are frequently explained by variations in atmospheric teleconnections, expressing the global or regional circulations. The two most well-known teleconnections are the Arctic Oscillation (AO) and the North Atlantic Oscillation (NAO).

The $\mathrm{AO}$ is a climate pattern characterized by winds whose direction is opposite clockwise around the Arctic at about $55^{\circ} \mathrm{N}$ latitude.The AO is a zonal symmetric seesaw between the sea level pressure in Polar region and moderate latitudes (Thompson, 1998).

When $\mathrm{AO}$ is in the positive phase, strong winds on high altitude circulating around the North Pole form a vortex ring that closes in place a much colder air over the Arctic.Because of that, the higher pressure in mid-latitudes pulls cyclones further to the north of the Arctic.When this turbulence be- comes weaker and the $\mathrm{AO}$ moves into a negative phase, it allows the intrusion of cold air masses to plunge into North America, Europe and Asia. When the $\mathrm{AO}$ is negative, the jet stream moves south, bringing with it cooler weather with precipitation. At that time, the pressure over the polar region is relatively high, while being low at midlatitudes (around $45^{\circ} \mathrm{N}$ ), especially in the oceanic mid-latitudes.The shift of winds from the western belt of northern Europe into the middle latitudes occurs, forming the storms that bring rain to the Mediterranean region.

The $\mathrm{AO}$ extends through the stratosphere, from 6 to $30 \mathrm{~km}$ above the Earth's surface.The object of analysis is the stratosphere due to the main role played by the polar vortex in winter.From November to April, deep low is established in the strathosphere of the northen hemisphere, which reaches the trophospheric levels.Also, there is a consid- 
erable thickness reduction of these atmospheric layers in winter which leads to a stratospheretrophosphere coupling (Baldwin et al., 200o).This strathosphere-trophosphere coupling has now been appropriately studied, but there are still some uncertainties with regard to its temporal and spatial irregularity.When the $\mathrm{AO}$ phase changes, the strengthening or weakening of the circulation around the North Pole begins in the stratosphere and it works its way through all atmospheric levels.lt appears that the phase and the strength of the $\mathrm{AO}$ are especially under the influence of stratospheric quasi-biennial oscillation $(\mathrm{QBO})$ in a manner that is consistent with the QBO influence on the polar vortex strength (Baldwin et al., 200o). The AO tends to be in a negative phase (weak vortex) when QBO has east flow.Wallace and others (Wallace et all, 2002) argue that the NAO is actually part of the $\mathrm{AO}$, including atmospheric circulation throughout the hemisphere.They say that this trend is strong and that the increased circulation around the North Pole can run processes in the stratosphere as well as those in the ocean. There are several factors influencing the occurrence of the different stratospheric anomalies in the North Pole.It is necessary to point to the solar activity, QBO, ENSO, volcanoes and greenhouse gases.

The NAO is the most important model of largescale natural climate variability in the northern hemisphere (Hurrell, 2003). It is a climatic phenomenon that occurs in the North Atlantic and is defined as difference in pressures between the ground-level high pressure centre over the Azores and the low pressure stationed over Iceland.NAO has two extreme phases - a positive phase (strong pressure activity at both centres) and a negative phase (low pressure activity at both centres).NAO is present throughout the whole year, but it is most pronounced in the amplitude of oscillations during the winter season (from December to March). A measure for the phase state of the NAO is an index called the North Atlantic Oscillation Index (NAOI).This analysis involved the use of Hurrell's index, using data of seasonal average air pressure differences between stations such as: Lisbon (Portugal) and Stykkisholmur/Reykjavik (Iceland). $\mathrm{NAO}$ phase changes cause changes in pressure regime, precipitation, temperature and wind over large areas, especially during boreal winter in the northern hemisphere (Bachmann, 2007); therefore, variations in the NAO are important for society and environment.The studies on the impact of the $\mathrm{AO}$ and the NAO on temperature and precipitation in Serbia (Reljin, et al., 20or; Reljin, et al., 2003; Jovanovic, et all, 20Io) point out the importance of the influence of these atmospheric oscillations during the winter months.
Some other works of the mentioned authors ( Jovanovic, et al., 2002) analysed the correlation between daily sum of precipitation during winter (DJF) at I2 synoptic stations and the $\mathrm{AO}$ and the $\mathrm{NAO}$ indexes.Coefficient correlations were ranging from 0.35 to 0.44 for the AOI, and from - 0.11 to - 0.14 for the NAOI.For the selected stations, regression equations were calculated showing a positive trend in precipitation for the period I9802006 , mostly as a result of the positive AO phase.

They also analysed (Reljin, et al., 2002) the NAOI impact on mean monthly anomalies of pressure, temperature and precipitation in the climate of Serbia and Montenegro in winter period for 195I-2002.The results showed a positive correlation between pressure, temperature and the $\mathrm{NAOI}$ and a negative correlation for precipitation. By using the EOF method, the spatial pattern of maximum variance is presented.

\section{Data}

There are 28 synoptic meteorological stations in Serbia.The analysis used data from 20 synoptic stations, as other stations did not have complete data series for the period 1958-2007.The following stations were included: Palic, Novi Sad, Kikinda, Vrsac, Belgrade, Loznica, Valjevo, S. Palanka, V. Gradiste, Negotin, Zajecar, Zlatibor, Pozega, Kragujevac, Kraljevo, Cuprija, Nis, Sjenica, Vranje and Dimitrovgrad.

The data sources are RHS of Serbia databases for temperature and precipitation data; and the NOAA database for the data on NAO and AO indexes (Appendix).

The data were analysed in Matlab and XLSTAT programs, while Surfer is used for graphical representation.

\section{Methods}

Climate indexes are diagnostic tools used to describe a state of climate system.In order to analyse meteorological data, linear and nonlinear methods are used to obtain a simpler interpretation of spatial and temporal variability of these data sets.

In the work of I. Reljin et al. (2003) SOM nonlinear method of neural networks is applied on precipitation and temperature on the territory of Serbia and Montenegro.This method's results are compared with results of the linear EOF method. Very similar but more detailed results can be obtained with non-linear methods since the nature of the analysed meteorological data is a nonlinear one.

In order to reduce data to a lower dimensionality while their structure remains unchanged, the principal component analysis (PCA) - in meteor- 
ology called the empirical orthogonal function (EOF) - was used (Lorenz, I956).Dimensionality reduction aims to reduce number of variables. Results are based on total variability. All variables should be represented by a linear combination of smaller groups of factors (principal components). The Pearson correlation coefficient (linear method) is used in this paper because it provides a significant insight into the similarities between different data sets and enables the representation of homogeneous geographical areas. Anomalies were calculated in relation to mean monthly values for the base period I97I-2000, the so called "normal." The first to be calculated were specific climatological normals for the period I96I-I990, and then the same was done for another period - I97I-2000. The anomalies of temperature and precipitation are shown here in comparison to the normal I97I2000.Correlation coefficients were calculated for the same values and for the normal I96I-1990 for all stations, and were the same as for the normal I97I-200o. For this paper, a normal I97I-200o was selected because the positive phase of the Arctic Oscillation was dominating at that time, causing temperatures higher than normal in a number of American States and in northern Eurasia; and causing cooler than normal weather in the Greenland-Labrador region.The linear relationship between the temperature anomalies and the atmospheric oscillations of each index for 20 synoptic stations in Serbia for a period of 50 years (I9582007) was calculated.

The same linear correlation was also used for the relationship between the precipitation anomalies and the index of atmospheric oscillations.For a significance level of 0.05 (i.e. $95 \%$ confidence interval) was used the two-tailed Student's t-test.The principal component analysis is applied on the months with the highest correlation coefficient for temperature anomalies (January) and precipitation (February).The EOF's rotation was performed in order to achieve better interpretation of results.

\section{Results}

Exploring the impact of the $\mathrm{AO}$ on weather in Serbia, it was found that during the period of 1958 2007 the positive $\mathrm{AO}$ phase was present in $47.3 \%$ of cases and the negative $\mathrm{AO}$ phase was present in $52.7 \%$ of cases (a total of 600 data). In the same period of 50 years, the NAO phase was present as a positive in $53 \%$ of cases and as a negative in $47 \%$ of cases.

Between the years 1970 and 2007, the positive $\mathrm{AO}$ phase was present in $51.1 \%$ of cases and the negative $\mathrm{AO}$ phase was present in $48.9 \%$ of cases, which indicates a longer period of time under the influence of the positive $\mathrm{AO}$ phases.In the period of $1970-2007$, the positive NAO phase was present in $54.4 \%$ of cases and the negative one was present in $45.6 \%$ of cases, which is also in favour of a more positive NAO phase effects.

The t-statistic is used; $\mathrm{t}=\mathrm{r}(\mathrm{N}-2)^{1 / 2} /\left(\mathrm{I}-\mathrm{r}^{2}\right)^{1 / 2}$, where $\mathrm{N}$ is the sample size $(\mathrm{N}=50)$, and $\mathrm{r}$ is the coefficient correlation. The number of degrees of freedom is $v=\mathrm{N}-2$. In this case, for the two-tailed t-test for the number of degrees of freedom $n=48$, a reliable value is: $t_{0.025}=2.30$. I use the two-tailed t-test, with $0.025 \%$ confidence interval on either side (total is $0.05 \%$ ), because it is not known in advance whether the correlation is a positive or negative one.The following are the example tests.

For the AOI and temperature anomalies I get the $\mathrm{t}$-stat $=5.476>2.30$, the null hypothesis is rejected.

For the AOI and precipitation anomalies obtained is the t-stat $=5.197>2.30$, the null hypothesis is rejected.

For the NAOI and temperature anomalies obtained is the t-stat $=6.087>2.30$, the null hypothesis is rejected.

For the NAOI and precipitation anomalies obtained is the t-stat $=3.792>2.30$, the null hypothesis is rejected. The t-test demonstrated that the null hypothesis can be rejected (Wilks, 2006).

\section{Results of the Principal Component Analysis Method - Correlation Matrix}

The Arctic and the North Atlantic oscillations are present throughout the whole year, but their impact differs in temperature and precipitation in different seasons.

The first result obtained by the PCA is correlation matrix.The Table I shows that the correlations between the $\mathrm{AOI}$ and the temperature anomalies are positive in January, February, March, August, September and partially in December.The correlations are negative in April, May, June, July and also negligible; while in October and November the correlations are also negative, but slightly larger.

Table 2 shows that the correlations between the NAOI and the temperature anomalies are negative only in April, May, June and July, and negligible. Significance of both oscillations with temperature anomalies is mostly present in March.The correlation coefficient was the highest in January and the maximum correlation is $0.6 \mathrm{I}$ for the $\mathrm{AOI}$ and 0.64 for the NAOI (Table 2).The correlations are also high and statistically significant in September.

We can see that the correlation between the $\mathrm{AO}$, $\mathrm{NAO}$ and precipitation in Serbia is negative in January, February, March, September, October and November (Tables 3 and 4). In other months, the correlation is combined, both positive and negative.In months with low correlations, this means 
Table 1. Correlation matrix [Pearson correlation coefficients] between the Arctic Oscillation index and temperature anomalies by months in Serbia for the period of 1958-2007 [Values in bold are different from 0 with a significance level alpha=0.05]

\begin{tabular}{|c|c|c|c|c|c|c|c|c|c|c|c|c|}
\hline Station & Jan & Feb & Mar & Apr & May & June & July & Aug & Sep & Oct & Nov & Dec \\
\hline Beograd & 0,36 & 0,18 & 0,41 & $-0,14$ & $-0,02$ & $-0,11$ & $-0,03$ & 0,18 & 0,34 & $-0,16$ & $-0,19$ & 0,00 \\
\hline Palic & 0,41 & 0,27 & 0,43 & $-0,14$ & 0,03 & 0,00 & 0,11 & 0,27 & 0,40 & $-0,07$ & $-0,17$ & 0,09 \\
\hline Novi Sad & 0,42 & 0,23 & 0,38 & $-0,16$ & $-0,01$ & $-0,02$ & $-0,02$ & 0,24 & 0,37 & $-0,12$ & $-0,19$ & 0,03 \\
\hline Sonbor & 0,45 & 0,29 & 0,38 & $-0,15$ & 0,03 & 0,01 & 0,10 & 0,28 & 0,37 & $-0,12$ & $-0,15$ & 0,07 \\
\hline S.Mitrovica & 0,38 & 0,22 & 0,35 & $-0,17$ & $-0,02$ & $-0,08$ & $-0,13$ & 0,20 & 0,32 & $-0,18$ & $-0,18$ & 0,03 \\
\hline Kikinda & 0,40 & 0,21 & 0,39 & $-0,14$ & 0,02 & 0,00 & 0,05 & 0,23 & 0,35 & $-0,11$ & $-0,20$ & 0,01 \\
\hline Loznica & 0,36 & 0,19 & 0,36 & $-0,19$ & $-0,03$ & $-0,12$ & $-0,06$ & 0,23 & 0,33 & $-0,22$ & $-0,16$ & 0,02 \\
\hline V.Gradiste & 0,33 & 0,13 & 0,40 & $-0,13$ & $-0,05$ & $-0,11$ & $-0,07$ & 0,12 & 0,22 & $-0,15$ & $-0,25$ & $-0,04$ \\
\hline Zlatibor & 0,29 & 0,13 & 0,38 & $-0,12$ & 0,00 & $-0,16$ & $-0,19$ & 0,11 & 0,32 & $-0,18$ & $-0,20$ & $-0,10$ \\
\hline Zaječar & 0,54 & 0,20 & 0,42 & $-0,12$ & 0,11 & $-0,14$ & $-0,12$ & 0,11 & 0,17 & $-0,13$ & $-0,15$ & 0,07 \\
\hline Vrsac & 0,27 & 0,17 & 0,22 & $-0,17$ & 0,01 & $-0,06$ & $-0,02$ & 0,19 & 0,20 & $-0,23$ & $-0,24$ & $-0,09$ \\
\hline Valjevo & 0,36 & 0,08 & 0,37 & $-0,16$ & $-0,01$ & $-0,14$ & $-0,07$ & 0,15 & 0,32 & $-0,19$ & $-0,20$ & $-0,01$ \\
\hline Dimitrov. & 0,22 & 0,01 & 0,34 & $-0,09$ & $-0,04$ & $-0,21$ & $-0,31$ & $-0,06$ & 0,16 & $-0,31$ & $-0,29$ & $-0,18$ \\
\hline S.Palanka & 0,35 & 0,12 & 0,36 & $-0,16$ & $-0,04$ & $-0,16$ & $-0,13$ & 0,14 & 0,21 & $-0,21$ & $-0,25$ & $-0,06$ \\
\hline Kragujevac & 0,35 & 0,10 & 0,35 & $-0,16$ & $-0,05$ & $-0,13$ & $-0,11$ & 0,10 & 0,22 & $-0,23$ & $-0,23$ & $-0,07$ \\
\hline Kraljevo & 0,33 & 0,11 & 0,36 & $-0,14$ & $-0,05$ & $-0,19$ & $-0,21$ & 0,08 & 0,25 & $-0,22$ & $-0,20$ & $-0,04$ \\
\hline Negotin & 0,61 & 0,28 & 0,45 & $-0,09$ & $-0,06$ & $-0,08$ & $-0,08$ & 0,12 & 0,33 & $-0,05$ & $-0,09$ & 0,15 \\
\hline $\mathrm{Nis}$ & 0,25 & 0,07 & 0,37 & $-0,10$ & $-0,06$ & $-0,22$ & $-0,19$ & 0,10 & 0,24 & $-0,25$ & $-0,25$ & $-0,11$ \\
\hline Sjenica & 0,16 & $-0,09$ & 0,32 & $-0,11$ & $-0,07$ & $-0,23$ & $-0,18$ & 0,06 & 0,25 & $-0,35$ & $-0,19$ & $-0,14$ \\
\hline Vranje & 0,19 & 0,01 & 0,36 & $-0,07$ & $-0,06$ & $-0,23$ & $-0,32$ & 0,00 & 0,25 & $-0,26$ & $-0,24$ & $-0,13$ \\
\hline
\end{tabular}

Table 2. Correlation matrix [Pearson correlation coefficients] between the Arctic Oscillation index and precipitation anomalies by months in Serbia for the period 1958-2007 [Values in bold are different from 0 with significance level alpha=0.05]

\begin{tabular}{|c|c|c|c|c|c|c|c|c|c|c|c|c|}
\hline Station & Jan & Fef & Mar & Apr & May & June & July & Aug & Sep & Oct & Nov & Dec \\
\hline Beograd & 0,56 & 0,18 & 0,41 & $-0,07$ & $-0,02$ & $-0,09$ & $-0,07$ & 0,24 & 0,33 & 0,04 & 0,12 & 0,23 \\
\hline Palic & 0,62 & 0,27 & 0,44 & $-0,03$ & $-0,03$ & $-0,04$ & $-0,01$ & 0,30 & 0,33 & 0,12 & 0,19 & 0,31 \\
\hline Novi Sad & 0,62 & 0,27 & 0,39 & $-0,07$ & 0,00 & 0,01 & $-0,11$ & 0,32 & 0,34 & 0,09 & 0,17 & 0,25 \\
\hline Sombor & 0,64 & $-0,41$ & $-0,27$ & 0,10 & 0,04 & $-0,10$ & $-0,04$ & 0,28 & $-0,48$ & $-0,34$ & $-0,27$ & $-0,29$ \\
\hline S.Mitrovica & 0,60 & 0,25 & 0,36 & $-0,06$ & $-0,01$ & $-0,04$ & $-0,07$ & 0,27 & 0,34 & 0,06 & 0,20 & 0,28 \\
\hline Kikinda & 0,61 & 0,21 & 0,40 & $-0,04$ & 0,02 & 0,01 & $-0,07$ & 0,27 & 0,33 & 0,10 & 0,19 & 0,27 \\
\hline Loznica & 0,56 & 0,21 & 0,36 & $-0,06$ & $-0,07$ & $-0,09$ & $-0,12$ & 0,24 & 0,34 & 0,00 & 0,16 & 0,25 \\
\hline V.Gradiste & 0,54 & 0,13 & 0,41 & $-0,02$ & $-0,02$ & $-0,04$ & $-0,07$ & 0,23 & 0,31 & 0,08 & 0,17 & 0,28 \\
\hline Zlatibor & 0,42 & 0,14 & 0,35 & $-0,02$ & $-0,03$ & $-0,14$ & $-0,11$ & 0,20 & 0,38 & 0,02 & 0,15 & 0,13 \\
\hline Zajecar & 0,64 & 0,25 & 0,46 & 0,00 & $-0,13$ & $-0,15$ & 0,00 & 0,21 & 0,28 & $-0,05$ & 0,02 & 0,25 \\
\hline Vrsac & 0,46 & 0,24 & 0,23 & 0,06 & 0,04 & 0,02 & 0,03 & 0,26 & 0,29 & 0,13 & 0,21 & 0,10 \\
\hline Valjevo & 0,55 & 0,08 & 0,36 & $-0,04$ & $-0,05$ & $-0,09$ & $-0,07$ & 0,22 & 0,34 & 0,01 & 0,14 & 0,24 \\
\hline Dimitrov. & 0,37 & 0,01 & 0,35 & 0,04 & 0,01 & $-0,16$ & $-0,11$ & 0,09 & 0,30 & $-0,03$ & 0,09 & 0,16 \\
\hline S.Palanka & 0,55 & 0,12 & 0,38 & $-0,03$ & $-0,03$ & $-0,10$ & $-0,08$ & 0,22 & 0,29 & 0,06 & 0,12 & 0,21 \\
\hline Kragujevac & 0,53 & 0,10 & 0,36 & $-0,02$ & $-0,03$ & $-0,14$ & $-0,06$ & 0,19 & 0,31 & 0,03 & 0,13 & 0,20 \\
\hline Kraljevo & 0,50 & 0,11 & 0,38 & $-0,05$ & $-0,01$ & $-0,12$ & $-0,13$ & 0,19 & 0,34 & $-0,01$ & 0,14 & 0,21 \\
\hline Negotin & 0,66 & 0,28 & 0,47 & $-0,02$ & $-0,05$ & $-0,11$ & 0,01 & 0,19 & 0,27 & $-0,03$ & 0,06 & 0,31 \\
\hline Nis & 0,46 & 0,07 & 0,39 & 0,03 & 0,00 & $-0,16$ & $-0,09$ & 0,23 & 0,31 & $-0,01$ & 0,14 & 0,18 \\
\hline Sjenica & 0,29 & $-0,09$ & 0,30 & 0,03 & $-0,04$ & $-0,24$ & $-0,05$ & 0,13 & 0,35 & $-0,06$ & 0,18 & 0,05 \\
\hline Vranje & 0,34 & 0,01 & 0,35 & 0,04 & $-0,03$ & $-0,19$ & $-0,17$ & 0,12 & 0,32 & $-0,01$ & 0,14 & 0,17 \\
\hline
\end{tabular}


Table 3. Correlation matrix [Pearson correlation coefficients] between the Arctic Oscillation index and precipitation anomalies by months, in Serbia for the period 1958-2007 [Values in bold are different from 0 with a significance level alpha=0.05]

\begin{tabular}{|c|c|c|c|c|c|c|c|c|c|c|c|c|}
\hline Station & Jan & Fef & Mar & April & May & June & July & Aug & Sep & Oct & Nov & Dec \\
\hline Beograd & $-0,49$ & $-0,42$ & $-0,36$ & 0,18 & 0,03 & 0,15 & $-0,06$ & 0,08 & $-0,34$ & $-0,28$ & $-0,29$ & $-0,24$ \\
\hline Palic & $-0,56$ & $-0,45$ & $-0,34$ & 0,05 & 0,08 & $-0,06$ & $-0,06$ & $-0,07$ & $-0,41$ & $-0,29$ & $-0,26$ & $-0,36$ \\
\hline Novi Sad & $-0,51$ & $-0,52$ & $-0,21$ & 0,16 & 0,08 & 0,04 & 0,15 & $-0,06$ & $-0,36$ & $-0,33$ & $-0,13$ & $-0,29$ \\
\hline Sombor & $-0,50$ & $-0,31$ & 0,39 & $-0,04$ & $-0,01$ & $-0,02$ & $-0,01$ & 0,11 & 0,33 & 0,08 & 0,19 & 0,28 \\
\hline S.Mitrovica & $-0,36$ & $-0,54$ & $-0,49$ & 0,21 & $-0,09$ & 0,26 & 0,11 & $-0,29$ & $-0,42$ & $-0,30$ & $-0,32$ & $-0,35$ \\
\hline Kikinda & $-0,49$ & $-0,53$ & $-0,35$ & 0,07 & 0,00 & $-0,02$ & 0,01 & 0,05 & $-0,20$ & $-0,38$ & $-0,22$ & $-0,36$ \\
\hline Loznica & $-0,35$ & $-0,47$ & $-0,24$ & $-0,49$ & 0,04 & 0,23 & 0,01 & $-0,15$ & $-0,29$ & $-0,34$ & $-0,19$ & $-0,27$ \\
\hline V.Gradiste & $-0,40$ & $-0,32$ & $-0,32$ & 0,13 & $-0,06$ & 0,18 & 0,20 & $-0,01$ & $-0,36$ & $-0,27$ & $-0,05$ & $-0,23$ \\
\hline Zlatibor & $-0,34$ & $-0,43$ & $-0,21$ & 0,10 & 0,06 & 0,22 & 0,24 & 0,01 & $-0,25$ & $-0,21$ & $-0,37$ & $-0,13$ \\
\hline Zajecar & $-0,54$ & $-0,55$ & $-0,49$ & 0,21 & $-0,01$ & 0,27 & 0,15 & $-0,07$ & $-0,35$ & $-0,25$ & $-0,32$ & $-0,21$ \\
\hline Vrsac & $-0,31$ & $-0,47$ & $-0,16$ & 0,02 & 0,01 & 0,28 & 0,02 & $-0,08$ & $-0,32$ & $-0,34$ & $-0,20$ & $-0,26$ \\
\hline Valjevo & $-0,40$ & $-0,40$ & $-0,23$ & 0,04 & $-0,01$ & 0,24 & $-0,02$ & $-0,06$ & $-0,26$ & $-0,28$ & $-0,27$ & $-0,14$ \\
\hline Dimitrov & $-0,44$ & $-0,55$ & $-0,38$ & 0,32 & $-0,04$ & 0,16 & 0,36 & 0,05 & $-0,30$ & $-0,16$ & $-0,38$ & $-0,19$ \\
\hline S.Palanka & $-0,45$ & $-0,42$ & $-0,40$ & 0,19 & 0,09 & 0,16 & 0,07 & 0,15 & $-0,15$ & $-0,29$ & $-0,31$ & $-0,22$ \\
\hline Kragujevac & 0,43 & $-0,46$ & $-0,35$ & 0,06 & 0,08 & 0,23 & $-0,02$ & $-0,01$ & $-0,26$ & $-0,24$ & $-0,31$ & $-0,27$ \\
\hline Kraljevo & $-0,39$ & $-0,40$ & $-0,30$ & 0,20 & $-0,02$ & 0,29 & 0,19 & $-0,01$ & $-0,38$ & $-0,17$ & $-0,35$ & $-0,19$ \\
\hline Negotin & $-0,57$ & $-0,48$ & $-0,39$ & 0,10 & $-0,05$ & 0,10 & 0,06 & $-0,05$ & $-0,39$ & $-0,21$ & $-0,34$ & $-0,22$ \\
\hline Nis & $-0,46$ & $-0,59$ & $-0,42$ & 0,18 & $-0,10$ & 0,18 & 0,02 & $-0,06$ & $-0,49$ & $-0,28$ & $-0,31$ & $-0,24$ \\
\hline Sjenica & $-0,35$ & $-0,50$ & $-0,34$ & 0,26 & 0,00 & 0,24 & 0,07 & 0,12 & $-0,44$ & $-0,44$ & $-0,27$ & $-0,33$ \\
\hline Vranje & $-0,52$ & $-0,60$ & $-0,45$ & 0,16 & $-0,03$ & 0,22 & 0,40 & $-0,02$ & $-0,39$ & $-0,27$ & $-0,34$ & $-0,39$ \\
\hline
\end{tabular}

Table 4. Correlation matrix [Pearson correlation coefficients] between the North Atlantic oscillation index and precipitation anomalies by months in Serbia for the period 1958-2007 [Values in bold are different from 0 with a significance level alpha=0.05]

\begin{tabular}{|c|c|c|c|c|c|c|c|c|c|c|c|c|}
\hline Station & Jan & Fef & Mar & Apr & May & June & July & Aug & Sep & Oct & Nov & Dec \\
\hline Beograd & $-0,36$ & $-0,28$ & $-0,28$ & 0,20 & 0,00 & $-0,04$ & $-0,11$ & 0,13 & $-0,19$ & $-0,18$ & $-0,28$ & 0,06 \\
\hline Palic & $-0,43$ & $-0,34$ & $-0,34$ & 0,22 & 0,16 & $-0,26$ & $-0,11$ & $-0,07$ & $-0,27$ & $-0,22$ & $-0,35$ & 0,02 \\
\hline Novi Sad & $-0,39$ & $-0,42$ & $-0,16$ & 0,26 & $-0,01$ & $-0,12$ & 0,02 & $-0,04$ & $-0,14$ & $-0,30$ & $-0,11$ & 0,04 \\
\hline Sombor & $-0,41$ & $-0,31$ & $-0,21$ & 0,25 & $-0,10$ & $-0,20$ & 0,05 & $-0,01$ & $-0,29$ & $-0,22$ & $-0,24$ & 0,06 \\
\hline S.Mitrovica & $-0,45$ & $-0,45$ & $-0,25$ & 0,17 & 0,00 & $-0,06$ & 0,15 & $-0,01$ & $-0,19$ & $-0,26$ & $-0,20$ & 0,00 \\
\hline Kikinda & $-0,41$ & $-0,43$ & $-0,28$ & 0,29 & 0,11 & $-0,13$ & 0,01 & 0,02 & $-0,15$ & $-0,26$ & $-0,25$ & 0,00 \\
\hline Loznica & $-0,19$ & $-0,29$ & $-0,22$ & $-0,42$ & 0,00 & $-0,07$ & 0,16 & $-0,07$ & $-0,28$ & $-0,15$ & $-0,10$ & $-0,06$ \\
\hline V.Gradiste & $-0,39$ & $-0,27$ & $-0,30$ & 0,08 & $-0,08$ & $-0,12$ & 0,22 & 0,15 & $-0,22$ & $-0,18$ & $-0,09$ & 0,00 \\
\hline Zlatibor & $-0,11$ & $-0,24$ & $-0,17$ & 0,25 & $-0,01$ & 0,04 & $-0,04$ & 0,15 & $-0,21$ & $-0,11$ & $-0,23$ & 0,08 \\
\hline Zajecar & $-0,41$ & $-0,42$ & $-0,42$ & 0,25 & $-0,05$ & 0,17 & 0,15 & 0,03 & $-0,27$ & -0162 & $-0,19$ & 0,03 \\
\hline Vrsac & $-0,09$ & $-0,34$ & $-0,07$ & 0,06 & $-0,01$ & 0,06 & $-0,08$ & 0,00 & $-0,12$ & $-0,16$ & $-0,28$ & 0,12 \\
\hline Valjevo & $-0,20$ & $-0,22$ & $-0,14$ & 0,21 & $-0,04$ & $-0,07$ & 0,09 & 0,07 & $-0,20$ & $-0,24$ & $-0,14$ & 0,08 \\
\hline Dimitrov. & $-0,40$ & $-0,42$ & $-0,38$ & 0,34 & $-0,04$ & 0,18 & 0,14 & 0,10 & $-0,23$ & $-0,25$ & $-0,36$ & 0,00 \\
\hline S.Palanka & $-0,26$ & $-0,24$ & $-0,38$ & 0,30 & 0,08 & 0,06 & 0,03 & 0,11 & $-0,25$ & $-0,28$ & $-0,22$ & 0,01 \\
\hline Kragujevac & $-0,28$ & $-0,30$ & $-0,32$ & 0,23 & 0,00 & 0,12 & $-0,09$ & 0,00 & $-0,26$ & $-0,23$ & $-0,26$ & $-0,03$ \\
\hline Kraljevo & $-0,21$ & $-0,21$ & $-0,25$ & 0,33 & 0,00 & 0,17 & 0,16 & 0,01 & $-0,23$ & $-0,13$ & $-0,25$ & 0,01 \\
\hline Negotin & $-0,37$ & $-0,39$ & $-0,37$ & 0,09 & $-0,08$ & 0,07 & $-0,02$ & $-0,07$ & $-0,31$ & $-0,14$ & $-0,08$ & 0,01 \\
\hline $\mathrm{Nis}$ & $-0,32$ & $-0,46$ & $-0,40$ & 0,20 & $-0,09$ & 0,17 & 0,10 & 0,01 & $-0,30$ & $-0,16$ & $-0,33$ & $-0,02$ \\
\hline Sjenica & $-0,22$ & $-0,39$ & $-0,35$ & 0,35 & 0,00 & 0,23 & 0,05 & 0,14 & $-0,23$ & $-0,22$ & $-0,25$ & $-0,03$ \\
\hline Vranje & $-0,40$ & $-0,40$ & $-0,47$ & 0,32 & $-0,01$ & 0,17 & 0,26 & $-0,01$ & $-0,25$ & $-0,15$ & $-0,28$ & $-0,19$ \\
\hline
\end{tabular}


that the $\mathrm{AO}$ and the NAO influence is very weak and does not cause changes in rainfall. Very significant are correlations greater than 0.4 and particular attention should be paid to them.

The highest correlation coefficient between the $\mathrm{AO}, \mathrm{NAO}$ and precipitation is in February (max - 0.60 to -0.46 for the $\mathrm{AO}$ and the $\mathrm{NAO}$, respectively). A negative correlation between the index of the Arctic Oscillation and the precipitation anomaly is visible in July and October.

The North Atlantic Oscillation has a negative correlation between the precipitation anomalies in the period from January to March and from September to November. In the positive NAO phase, which brings the Mediterranean precipitation to our region from the southwest, as the NAO index increases, the precipitation in Serbia will be less than in other parts of Serbia.If the invasion of oceanic air masses is more active in summer months, the summer will be rainy and fresher, and if it happens in winter months, the consequences are heavy and snowy precipitation and less cold winters.At reduced ocean impact during the summer months, great heat and drought occur; while in winter, there are lighter snowy precipitation and higher cold spells.

Principal component analysis determines variables communality (common variance and communality estimate).Communality explains selected principal components that contribute the most to mutual correlations of original variables. Communality of variable is equal to the sum of the squares of loading for the main components

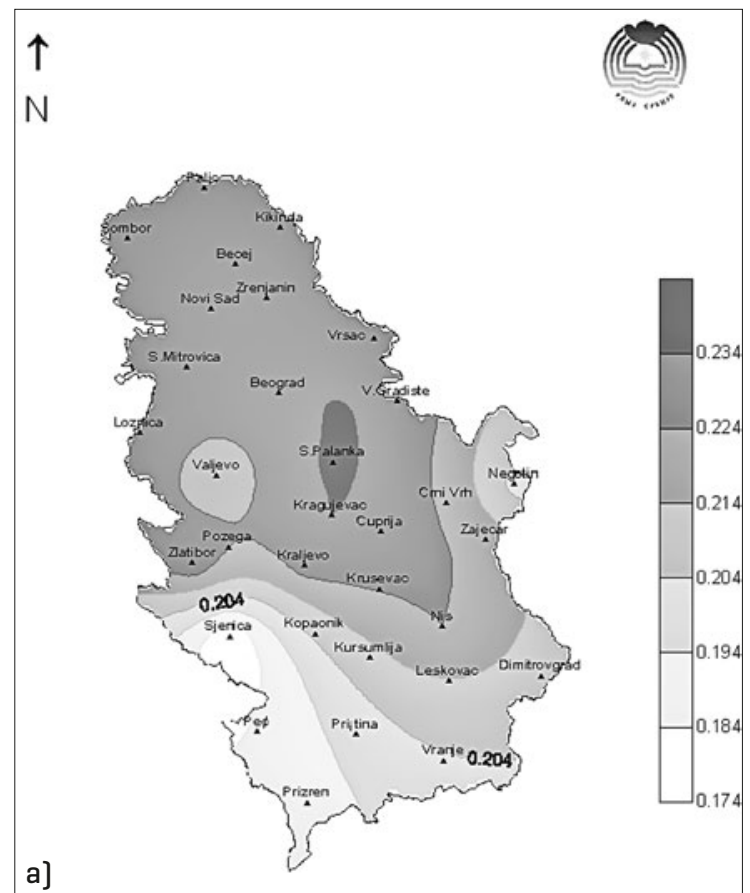

of the variable.Each eigenvalue explains a certain percentage of the total variability.Extraction is an order of constructing of eigenvalues that get a specific part of the total variance.When the extraction is stopped, the remaining variance is not statistically significant.

\section{PCA for the AO and the NAO Influence on the Temperature Anomaly in January}

With three eigenvalues (principal components) the $79 \%$ of total variance is explained.The first eigenvalue explains $59 \%$ of the variance, and the second one explains II.5\%.Together, the first and the second eigenvalue explain $70.5 \%$ of variance.The extraction can be completed with the two eigenvalues (depending on the extraction criteria) as they explain more than $70 \%$ of the variance.The sample EOFI is more important than the sample $\mathrm{EOF} 2$, except for the temperature anomalies in Sjenica (Figure I).

Sjenica is located in the south-western part of Serbia at an altitude I000-I030 $\mathrm{m}$, and on the Pester plateau.The station itself is located in a valley, which leads to accumulation of air, therefore the ventilation power in Sjenica valley is low. In winter, snow cover affects the decrease of air temperatures in lower layer and the occurrence of temperature inversions. It often lowers the relative humidity and the impact on the occurrence of fog and low temperature, which is confirmed here.

PCI and PC2 (Figure 2) show accordance with the observed positive temperatures tendency in

Figure 1. Spatial pattern of the influence of the AO and the NAO on temperature anomaly a] EOF1 [59\% explained variances] and b] EOF2 [11.5\% variances] 


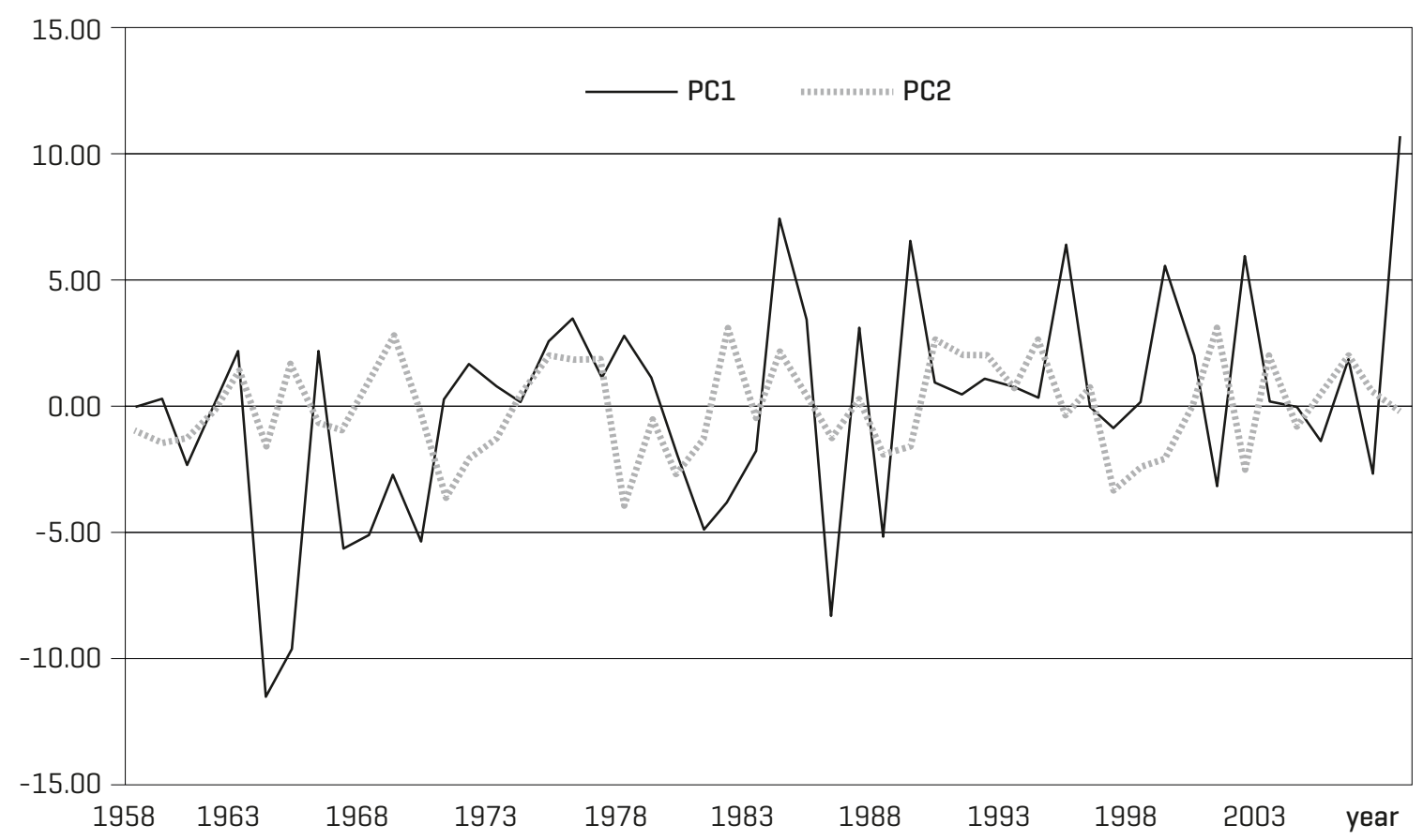

Figure 2. Temporal pattern of the influence of the $A O$ and the NAO [PC1 and PC2] on temperature anomaly for January for the period 1958-2007

recent years (since I990), and that both PC have the same tendency towards positive values.

The EOFI is a very good baseline data useful to explain the spatial pattern of the AO and NAO influences on temperature anomaly in January.The EOF2 is expressed only in the south and in the east of Serbia, but it was much smaller portion of the total variance.The prevailing meridional position of the river

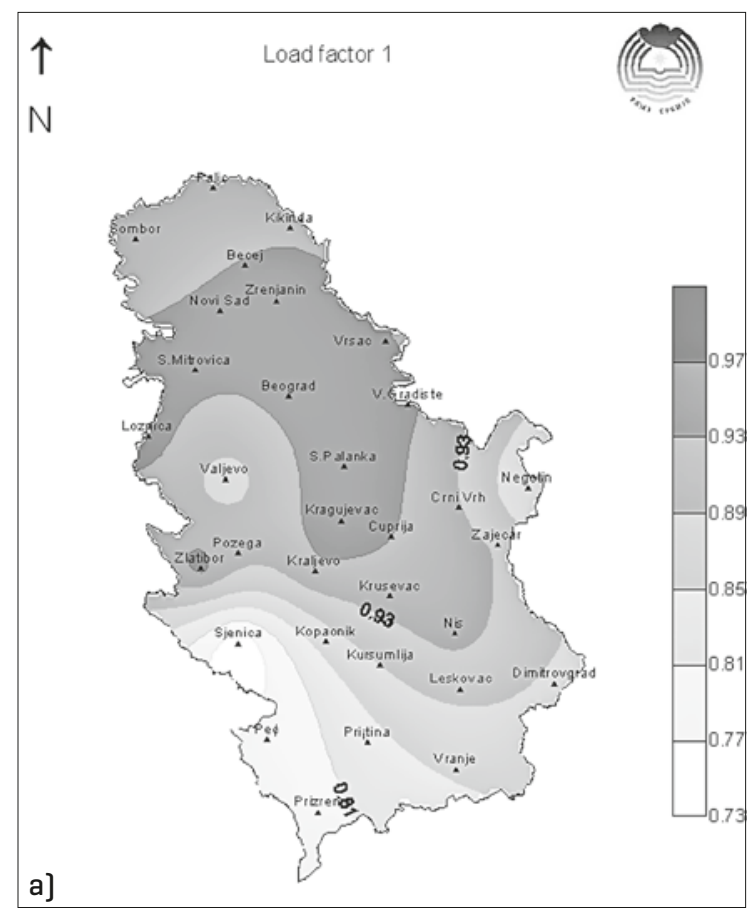

valleys and plains in the north of Serbia allows deep penetration of polar air masses into south.

Assessment of components (factor scores) is a linear composite of the optimally weighted observed variables.

Factor loadings are equivalent to bivariate correlations between the observed variables (temperature anomalies at stations) and the compo-

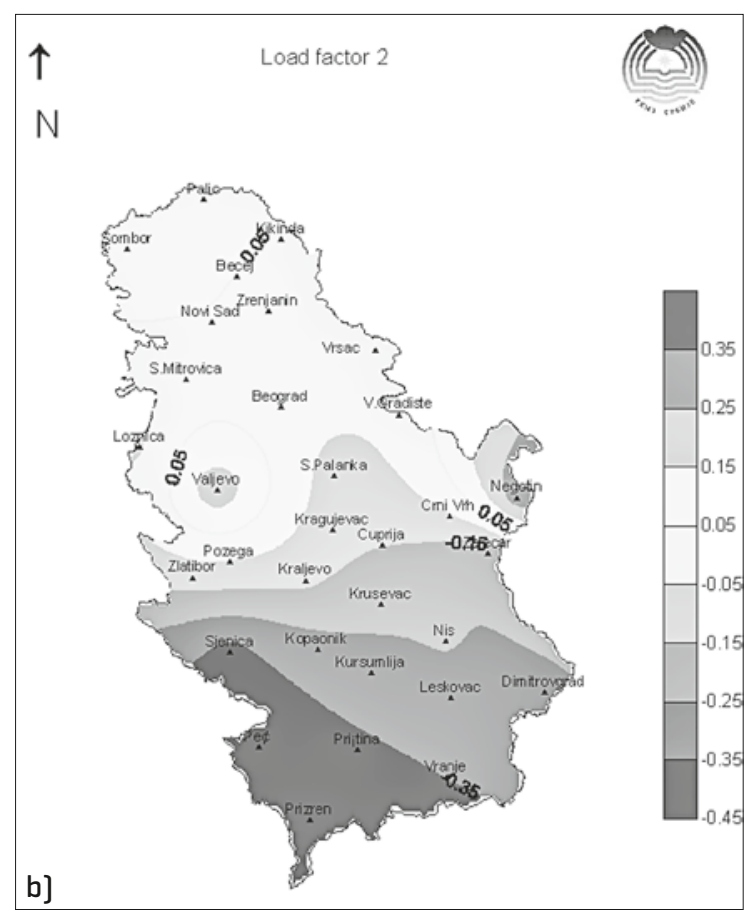

Figure 3. Factor loadings for temperature anomalies under the influence of the $N A O$ and the $A O$ a] the first factor and $b$ ] the second factor 

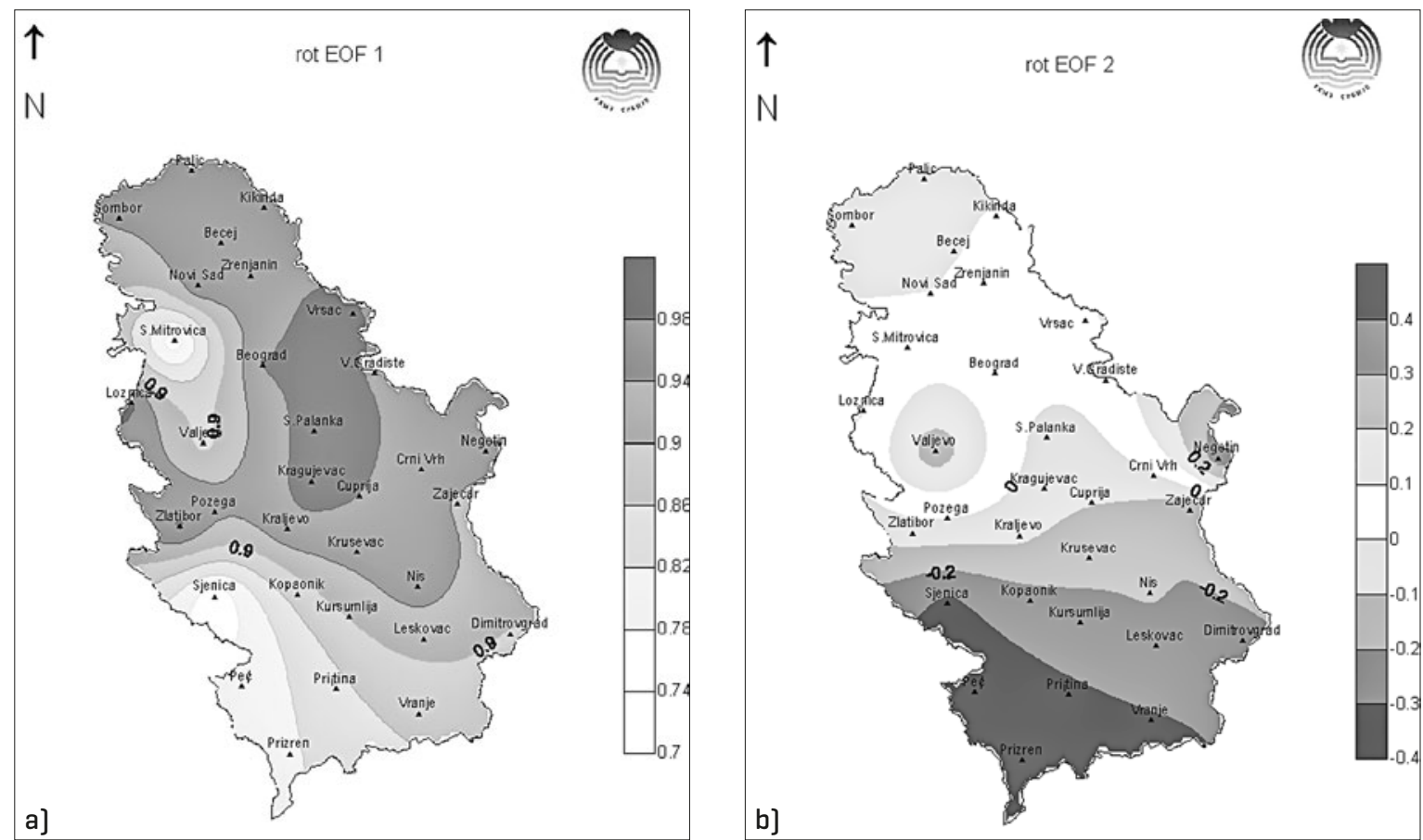

Figure 4. Varimax rotations of the $\mathrm{AO}$ and the NAO influence on temperature anomaly a] rot EOF1 and b] rot EOF2

nents.From the factor loadings we see variables contribution to main components.The correlation between variables and EOF's (Figure 3 ) shows high correlation of the variables and the first EOF (90\%), except for the temperature anomalies in Sjenica, South Serbia (Vranje and Dimitrovgrad) and East Serbia (Negotin).The air temperature in the long-term period shows a negative trend in the south-eastern part of Serbia (areas of Vranje and Dimitrovgrad) and in the eastern Serbia (Negotin), while in the most of Serbia a positive temperature trend is recorded.

\section{The Results of Varimax Rotation on Temperature Anomaly}

Factor analysis generates multiple solutions for the same data set.Any solution is a rotation. In each rotation, we have different coefficient and different interpretation.For orthogonal (varimax) rotation the factors are at right angles and not correlated.The inherent value of factor where each of them corresponds to a representative of one dimension.After the varimax rotation of principal components, they retained the overall variance.

The first component (Figure 4) interprets the spatial pattern much better than the second component. As with the first factor (Figure 3), the spatial pattern after varimax rotation (Figure 4a) confirms the already shown impact for temperature anomalies.Two areas are distinguished (the southern part of Serbia and the western part of Serbia, especially around S. Mitrovica, Loznica and Valjevo) as areas in which some other local factors also have influence (e.g. relief, thermal factors, water, etc.). By comparing Figure $3 \mathrm{~b}$ and $4 \mathrm{~b}$, we see that the rot EOF2 after varimax rotation confirmed the spatial pattern obtained with the EOF 2.This tells us that the rotation is not necessary in this case. Already obtained spatial patterns are only confirmed by varimax rotation.

\section{PCA for the AO and NAO Influence on Precipitation Anomalies in February}

The first eigenvalue explains $46.2 \%$, the second - II. $5 \%$, the third $-8.7 \%$, and the fourth explains $6.7 \%$ of the total variance. Only with four eigenvalues, the $73 \%$ of the variance is explained. This suggests that precipitation is significantly affected by some other factors besides the $\mathrm{AO}$ and the NAO oscillations (geographical location, relief and local influences, etc.)

Eigenvectors are approximately 0.2 and the EOFI is dominant. The EOF2 is expressed in Loznica, Valjevo and Belgrade.

The factor score explains where some of the variables retained the principal component.

Correlations between variables and principal components (Figure 7) are less for the precipitation anomalies (about o.8) than for the temperature anomalies.

\section{Results of Varimax Rotation for Precipitation Anomalies}

Varimax rotation seeks to maximize the variance in columns of the factor pattern. After varimax rotation, we see that the first EOF explains 44.I3\% 

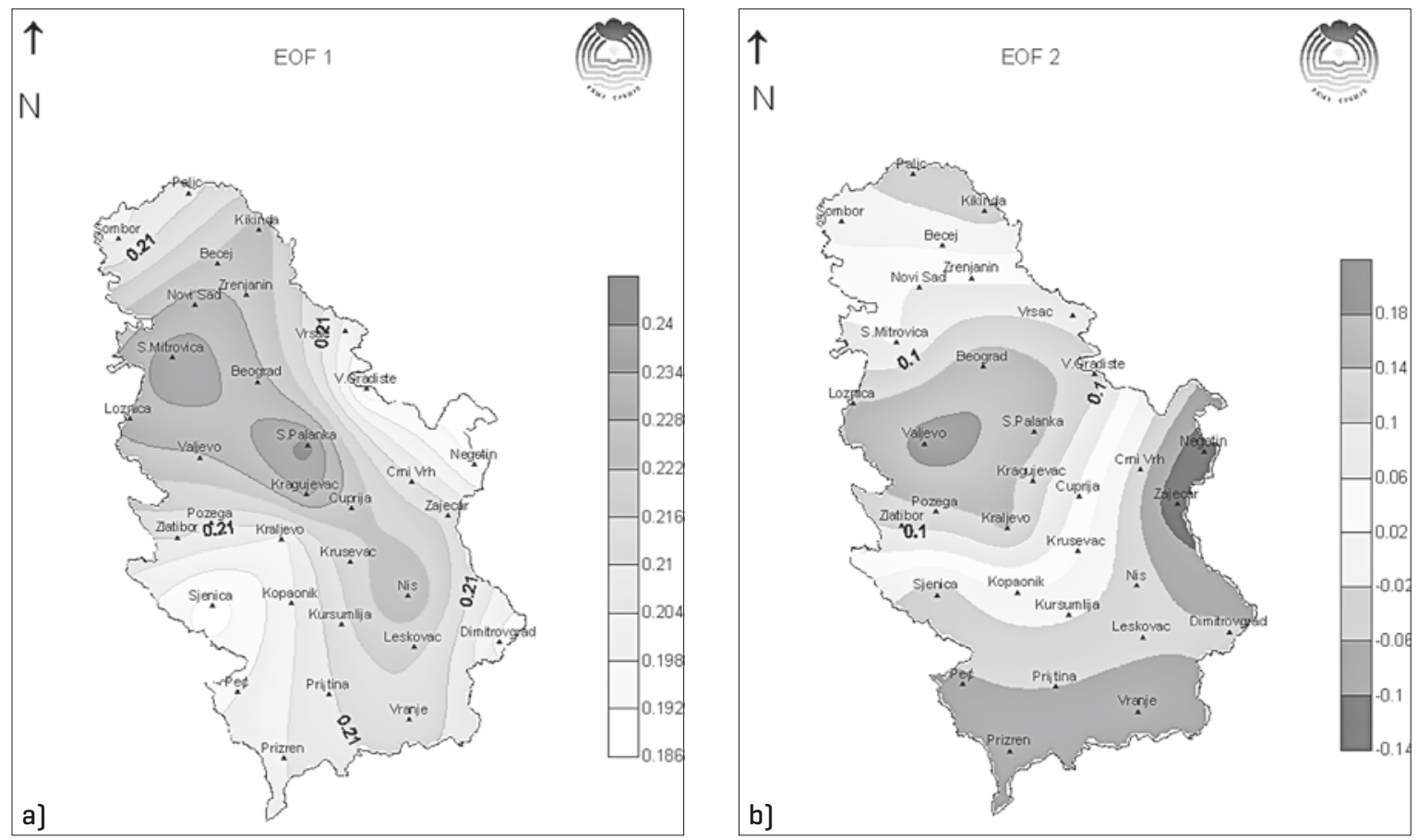

Figure 5. Principal components of precipitation anomalies in Serbia for the period 1958-2007 in February, a] EOF1 and b] EOF2

of the variance, and that the second one explains I2.4\% of the variance.The percentage of explained variance should be kept in rotation. The axes of the coordinate system are rotated and the EOFs are projected onto them.

After the varimax rotation, the EOFI values were only slightly reduced for some stations (northern Vojvodina, eastern and southern Serbia), while increased for others. Negative values of the second mode have grown in the north of Vojvodina (Sombor, Palic), East Serbia (Kikinda, Zajecar, Negotin) and South Serbia (Nis, Sjenica, Vranje, Dimitrovgrad). This means that the parts of Serba where values of the second mode have increased have slightly different spatial pattern than shown in the first mode.The second mode affects the character-

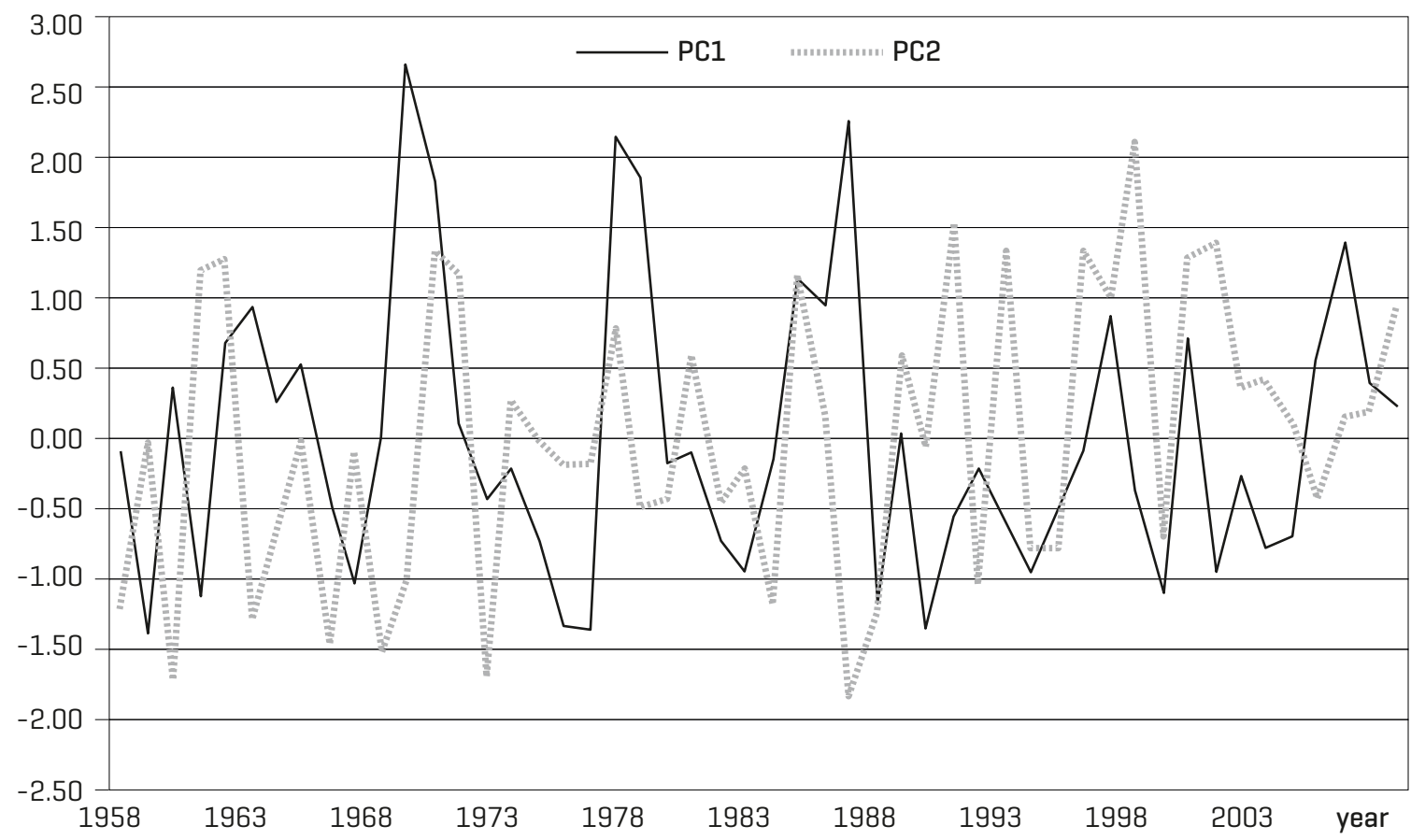

Figure 6 Temporal patterns of the AO and the NAO effects [PC1 and PC2] for February, precipitation for the period 1958-2007 

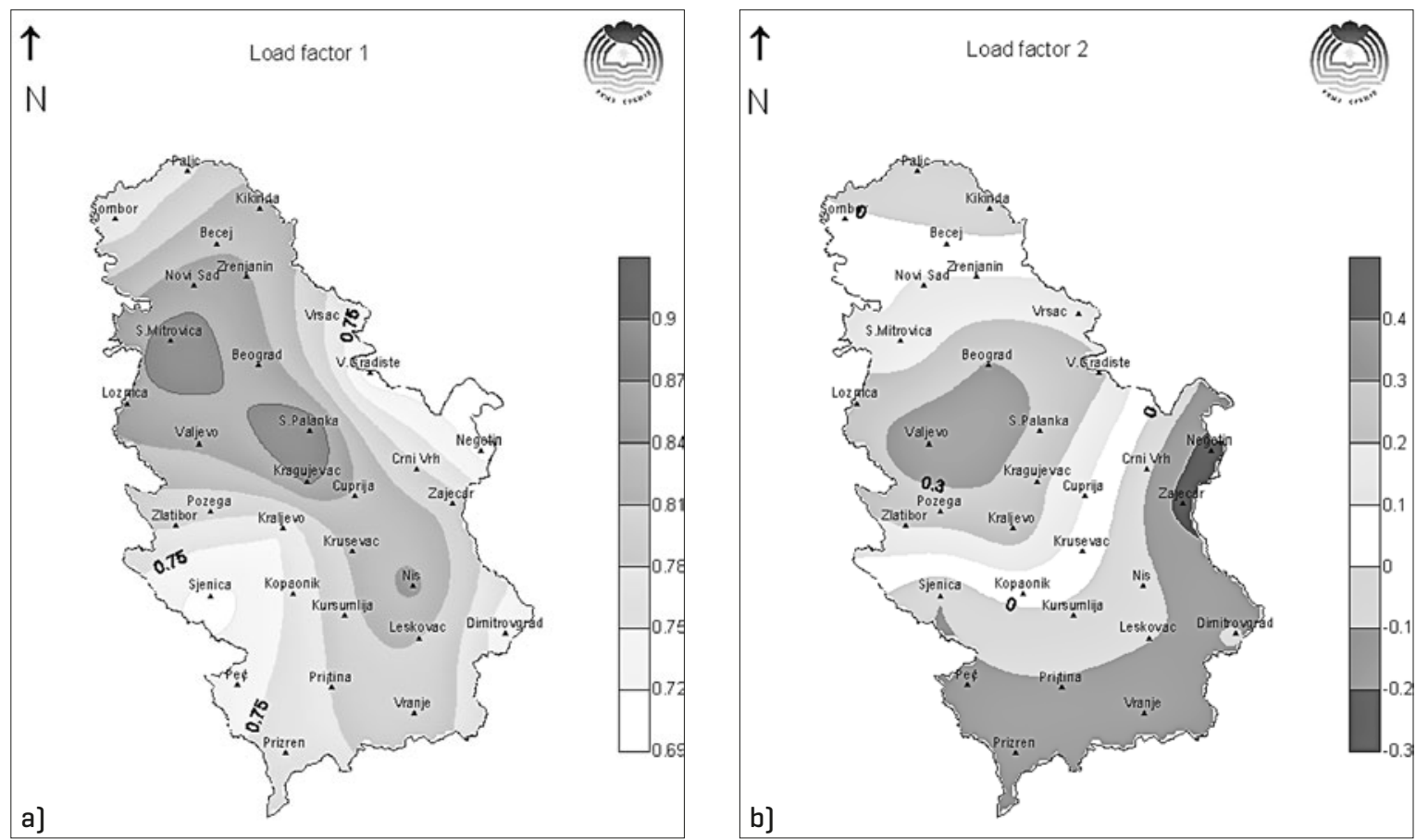

Figure 7. Factor loadings under the influence of the $A O$ and the NAO precipitation anomalies for a] the first factor and $b$ ] the second factor

istic spatial pattern of precipitation by the impact of oscillations in the northern, eastern and southern Serbia, contrary to the manifest general tendencies of precipitation in other areas.Special attention is given to the second mode for Zajecar, Negotin and Vranje.The correlation between the variables and PC (factors) explains the orientation of how they may be related. If the correlation is higher, the extracted PC is better to represent the baseline var-
iables.Rotation of PC shows (Figure 8) that there are other influences on Negotin and Zajecar.When cloudiness with rain comes from the Mediterranean or the Atlantic, Negotin Region remains free of snow for a long period, as opposed to the central Serbia that is already covered with snow. Conversely, when wet and cold waves come from the east or northeast, Negotin Region gets snow cover earlier than other parts of Serbia.
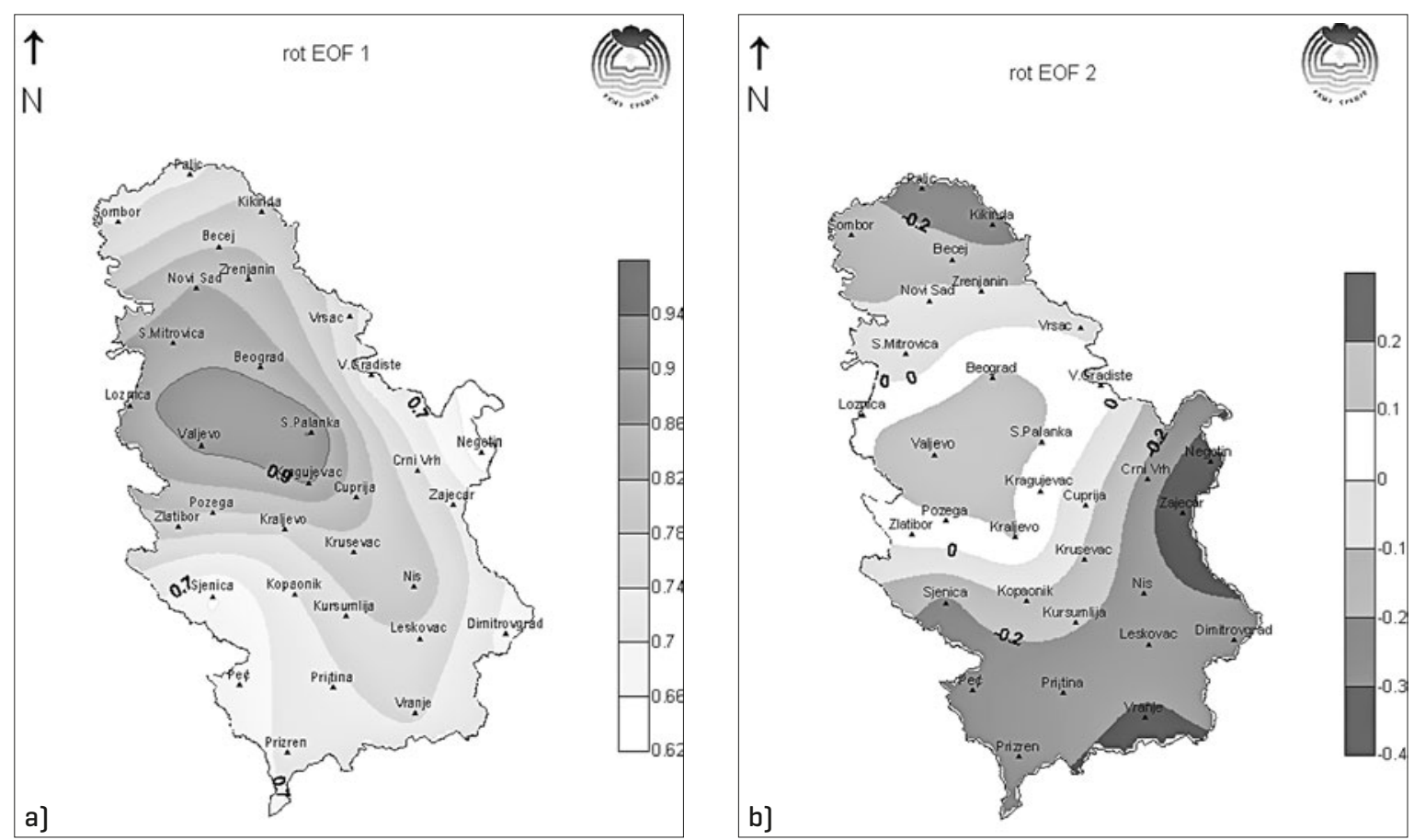

Figure 8. Varimax rotation of the $A O$ and the NAO influence on precipitation anomalies a] rot EOF1 b] rot EOF2 
Negotin is located in a plain surrounded by mountain ranges (Miroc, Crni Vrh and Deli Jovan) and by an open space on the eastern and southern sides that make the Negotin Region the most continental part of East Serbia.This part of East Serbia has the longest duration of snow cover. In winter usually blows the west and north-west wind (known as "Gornjak").Since coming through the Homolje Mountains, it always comes as a cold wind bringing sudden and heavy precipitation. When it is quiet, Negotin is the coldest place in Serbia and therefore its name "Serbian Siberia." Kosava wind (a southeast wind blowing from the Carpathians) is also common winter wind in this area.This wind is always cold, weaker than Gornjak but causing several days of fine snow falling.

\section{Conclusion}

A positive correlation between the Arctic Oscillation Index and the temperature anomaly is visible in Serbia, in the period from January to March and in September. A negative correlation between the Arctic Oscillation Index and precipitation anomaly is visible in July and October.

The Arctic Oscillation influences the precipitation anomalies in Serbia in the period from September to March and has a negative correlation of about $\mathrm{r}=-0.4$ to -0.6 .

The North Atlantic Oscillation affects the temperature anomalies as a positive correlation in the period from November to March, and then in August and September. The strongest correlation was in January $(\mathrm{r}=0.66)$.

The North Atlantic Oscillation has a negative correlation with precipitation anomalies between January and March $(\mathrm{r}=0.48)$, and from September to November.In Serbia, the Arctic Oscillation has a slightly stronger impact on precipitation anomalies than the North Atlantic Oscillation, but the situation is reversed when it comes to the temperature anomalies.

Generally, the Artic Oscillation and the North Atlantic Oscillation together affect the temperature anomalies in Serbia in the period from January (EOF analysis) to March and in September. The influence of both oscillations on precipitation anomaly can be seen in the period JanuaryMarch and September-November.Knowledge of these correlations can be used in climatological forecasts.

The results of PCA methods via EOFI and EOF2 show the spatial pattern of the temperature in January and the precipitation in February. With two principal components, the $70 \%$ of the variance in temperature anomalies is explained, while four principal components explain the precipitation anomalies.This shows that the precipitation in Serbia is influenced by some other factors apart from the analysed atmospheric oscillations.The leading factors (linear combinations of variables) are better correlated with temperature anomalies (90\%) than with anomalies of precipitation (80\%). Through the rotation of the EOF, it is shown that the effects of the $\mathrm{AO}$ and the $\mathrm{NAO}$ on the eastern and southern Serbia are different from the other parts.For analysis and future climatological forecast, it is needed to apply some other additional statistical methods and to include some other oscillations as well, such as QBO and ENSO.

\section{Acknowledgements}

I want to thank Brankica Drakula on a technical data processing.

\section{Appendix}

The web-site of the teleconnection patterns:

AO: http://www.cpc.noaa.gov/products/precip/CWlink/pna/ao_index.html

NAO: http://www.cpc.noaa.gov/products/precip/CWlink/pna/nao_index.html

\section{References}

Bachmann, N. 2007. The North Atlantic Oscillation (NAO). Termpaper Writing for MSc Biogeochemistry and pollutant dynamics, ETH Zurich.

Baldwin, M.P., Gray, L.J., Dunkerton, T.J., Hamilton, K., Haynes, P.H., Randel, W.J., Holton, J.R., Alexander, M.J., Hirota, I., Horinouchi, T., Jones, D.B.A., Kinnersley, J.S., Marquardt, C., Sato, K., Takahashi, M. 20or. The Quasi-Biennial Oscillation. Reviews of Geophysics 39, I79229.

Hurrell, W.J., Kushnir, Y., Ottersen G., Visbeck, M. 2003. An Overview of the North Atlantic Oscillation. Geophysical Monograph 134, American Geophysical Union, doi:I0.I029/134GMoI

Jovanović, G., Reljin, I., Savić, T. 2002. NAO Influence on Climate Variability in FRY. I $^{\text {th }}$ International Conference on Carpathian Meteorology, Belgrade.

Jovanović, G., Reljin, I., Reljin, B. 2008. The influence of Arctic and North Atlantic Oscillation on precipitation regime in Serbia. XXIV the Conference of the Danubian countries on the hydrological forecasting and hydrological bases of water management, Slovenia, Bled.

Jovanović, G., Reljin, I., Reljin, B. 2oro. The Influence of Dominant Global Climate Phenomena ENSO, NAO and AO on Climate in Serbia. European Conference on Applied Climatology I3I7 September 20Io, Zurich, Switzerland. 
Lorenz, E. 1956. Empirical Orthogonal Functions and Statistical Weather Prediction. Massachusetts institute of technology department of meteorology, Cambridge, Massachusetts.

Reljin, I., Jovanović, G., Reljin, B. 200I. The climate signal analysis through linear and nonlinear methods. in Proc. XI Conf. ISTET'or, Linz (Austria).

Reljin, I., Reljin, B., Jovanović, G. 2002. Clustering of Climate Data in Yugoslavia by use of SOM Neural Network. in Proceedings and CD of the $20026^{\text {th }}$ International seminar on Neural Network Applications in Electrical Engineering, IEEE, Belgrade.

Reljin, I., Jovanović, G., Reljin, B. 2003. The Use of SOM Neural Network for Precipitation Pattern Recognition in Yugoslavia. I8 ${ }^{\text {th }}$ International Conference on Carpathian Meteorology, Belgrade.
Reljin, I., Jovanović, G., Reljin, B. 2003. EOF analiza polja temperatura i padavina u Srbiji i Crnoj Gori tokom zime ", Konf. Informacion etehnologije, IT- Žabljak.

Thompson, D.W.J., Wallace, J.M. 1998. The Arctic Oscillation signature in the wintertime geopotentional height and temperature fields. Geophysical Research Letters 25, 9, I297-1300.

Tošić, I. 2004. Spatial and temporal variability of winter and summer precipitation over Serbia and Montenegro. Theoretical and applied climatology 77, 47-56.

Wallace, J.M., Thompson, D.W.J. 2002. Annular Modes and Climate Prediction? Physics Today $55,28-33$.

Wilks, S.D. 2006. Statistical methods in the Atmospheric Sciences. International geophysics Series, Volume 9I. 